\title{
Commercial High Explosives
}

\author{
Otto Ringgenberg* and Jörg Mathieu ${ }^{a}$
}

\begin{abstract}
Non-military explosives are used mainly for mining and tunnel construction, for building demolition and for various special uses such as setting off avalanches and for seismic investigations. Common to all explosives is their heterogeneous structure, the great work capacity (blast effect) and the advantage that the detonation releases only small amounts of poisonous explosion gases. Modern explosives for tunnel construction can be pumped and are capable of exploding only on site, by the addition or chemical generation of microbubbles. With the introduction of electronic detonators, explosive technology entered a new era. These detonators are very safe and precise, and it is possible to program up to 1600 detonators in one blasting operation.
\end{abstract}

Keywords: Blast effect · Detonator · Explosive plating · Explosives · Tagging

\section{Introduction}

In contrast to military explosives, which are mostly based on uniform molecules, explosives for non-military use are composed of oxidising, reducing, sensitising, and inert components. In order that the greatest possible explosive or blast effect can be achieved, and that the smallest possible amounts of the poisonous explosion gases $\mathrm{CO}$ and $\mathrm{NO}_{\mathrm{x}}$ are created in the detonation, the mixtures are mostly adjusted to a balanced to positive oxygen balance.

Traditional explosives are made sensitive by means of blasting oils such as glycerol trinitrate, nitroglycol or mixtures of these two. Explosives such as TNT are added as well. Modern formulations are characterised by high stability during storage and an insensitive behaviour. They are made capable of detonation only on site by introducing finely distributed gas bubbles.

Due to the heterogeneous structure of non-military explosive formulations, a high proportion of non-ideal conversion during the detonation occurs, which does not contribute to sustaining the shock front. Consequently these explosives, in contrast to mil-

${ }^{\star}$ Correspondence: O. Ringgenberg

TSSA Tunnel Service AG

Walchistrasse 30

$\mathrm{CH}-6078$ Lungern

Tel.: +41416797790

Fax: +41416797795

E-Mail: tssa@tunnelservice.ch

aarmasuisse

Science and Technology

Feuerwerkerstrasse 39

$\mathrm{CH}-3602$ Thun itary explosives, exhibit a strong propulsive effect (work capacity or blast effect), but only a restricted ability to accelerate metals (brisance).

\section{Historical Development}

The beginning of work with explosives in mining, and therefore also in tunnel construction, started in 1627 . In that year, the miner Caspar Weindl detonated in Slovakia the first documented underground explosion, using black powder. From there on, the customary method of driving shafts by 'Feuersetzen', working with miners' hammers and iron tools, was slowly replaced.

Until the second half of the 19th century black powder remained the only explosive used in mining and tunnel construction. Over 200 years after black powder was first used, the invention of DYNAMITE by Alfred Nobel in 1865 brought a change to working with explosives. Nobel succeeded in making the blasting oil - better known as glycerol trinitrate, which was actually discovered 20 years earlier, safe to handle by absorbing it into kieselguhr. With the invention of this highly explosive material, the forerunner of all present-day gelatinous explosives, and the introduction of drilling by machine, the necessary conditions for modern tunnel construction were created.

A patent for an explosive without blasting oil, but based on ammonium nitrate, had already been applied for in Sweden in 1867. The first ANFO (Ammonium Nitrate Fuel Oil) explosives containing no blasting oil gained world-wide acceptance only in the mid 1950s. These consist solely of ammonium nitrate as oxidizing agent and mineral oil as the combustible component.

These cost-effective explosives have attained world-wide importance because they are easy to produce and very safe to handle, even as freeflowing loose materials. Their high sensitivity to moisture, however, due to the strongly hygroscopic behaviour of the ammonium nitrate, limits their possible use to dry drill-holes, which means that their use in tunnel construction is severely restricted. In 1956, the American Melvin A. Cook was the first one to succeed in making ANFO-like explosives water-resistant. He developed an explosive mixture made up of water, ammonium nitrate and aluminium, and used it successfully. Because of their paste-like, granular, sludgy consistency, explosive mixtures of this kind are referred to as 'slurry explosives'. In 1970, simple and water-resistant nitrate explosives were successfully developed in the USA. These are now the latest generation of explosives which contain water but no inherently explosive ingredients.

\section{Composition of Non-military Explosives}

\subsection{Gelatinous Explosives}

For over 120 years the most commonly used non-military explosives have been the gelatinous explosives. They consist mainly of a mixture of blasting oil gelatinised with nitrocellulose - so-called explosive gelatine - and the oxidising agent ammonium nitrate. Normally the proportion of gelatinised blasting oil is between 20 and $40 \%$. With that percentage of blasting oil, these explosives are without exception sufficiently sensitive to be detonated by the energy of 
Table 1. Example of an ammonium saltpetre gelatine composition

\begin{tabular}{|c|c|c|}
\hline Components & Content [\%] & Effect \\
\hline Nitroglycerine & 24.5 & Sensitisation \\
\hline $\begin{array}{l}\text { Collodion wool } \\
\text { (nitrated cellulose with } \\
11 \% \mathrm{~N} \text { content) + water }\end{array}$ & 1.5 & $\begin{array}{l}\text { Gelatinisation of the nitroglycerine. } \\
\text { The water serves to stabilise the collodion } \\
\text { wool }\end{array}$ \\
\hline Ammonium nitrate & 61 & Oxidising agent \\
\hline Barium sulphate & 3 & Flame reducing agent \\
\hline Cellulose & 4.5 & $\begin{array}{l}\text { Reducing agent and optimisation of } \\
\text { mechanical properties }\end{array}$ \\
\hline Dinitrotoluol & 5.5 & Source of energy \\
\hline
\end{tabular}

the form of a 'water-in-oil emulsion' with the help of emulsifying agents. Similar to ANFO explosives and slurries of the blasting-agent type, they contain no components classified as pure explosive materials. Until hollow microspheres or gas-forming chemical ingredients $e . g$. nitrites in combination with thiourea are added, the material matrix of emulsion explosives is therefore incapable of detonation. This characteristic and the insensitivity to impact and friction is not achieved by any other type of explosives. They are the safest commercial explosives in terms of handling today. Another positive asset is the particularly high resistance to water and the only slight toxic composition of the explosive clouds in respect of $\mathrm{CO}$ and $\mathrm{NO}_{\mathrm{X}}$. Emulsion explosives are manufac- a single blasting cap. Gelatinous explosives can be used only in the form of cartridges. As gelatinous explosives age, migration of the blasting oils takes place. This process is greatly accelerated by large temperature fluctuations. A shelf life of two years is therefore usually specified for gelatinous explosives. Table 1 shows an example of a gelatinous explosive composition.

\subsection{Ammonium Nitrate Fuel Oil (ANFO)}

ANFO consists of $94 \%$ granulated porous ammonium nitrate and $6 \%$ oil as fuel. ANFO explosives are classified as socalled hard-to-detonate explosives. They can be detonated only when activated sufficiently by a booster charge, and are therefore responsive to blasting caps only to a limited extent. Fig. 1 illustrates the open explosive mining of lime with a mixed charge of ANFO and gelatinous explosive.

\subsection{Slurry Explosives}

Slurry explosives are mixtures of aqueous, inorganic salt solutions and non-soluble liquid and/or solid oxidisable reaction partners. Components providing oxygen are various nitrates, most commonly ammonium nitrate. Characteristic of this type of explosive is the high water content of $10-20 \%$, in which some or all of the salts which provide oxygen are present in solution. From this water content, the frequently used name 'water-gel' is derived. Two types of slurries are known. Slurry explosives (SE), which are rendered sensitive with explosive materials, and slurry blasting agents (SBA), which contain no inherently explosive materials and are sensitised by introducing a large number of very small cavities, so-called hot spots.

\subsection{Emulsion Explosives}

In general the term emulsion explosives is used for mixtures of high-concentration salt solutions containing oxygen and combustible components. They are stabilised in

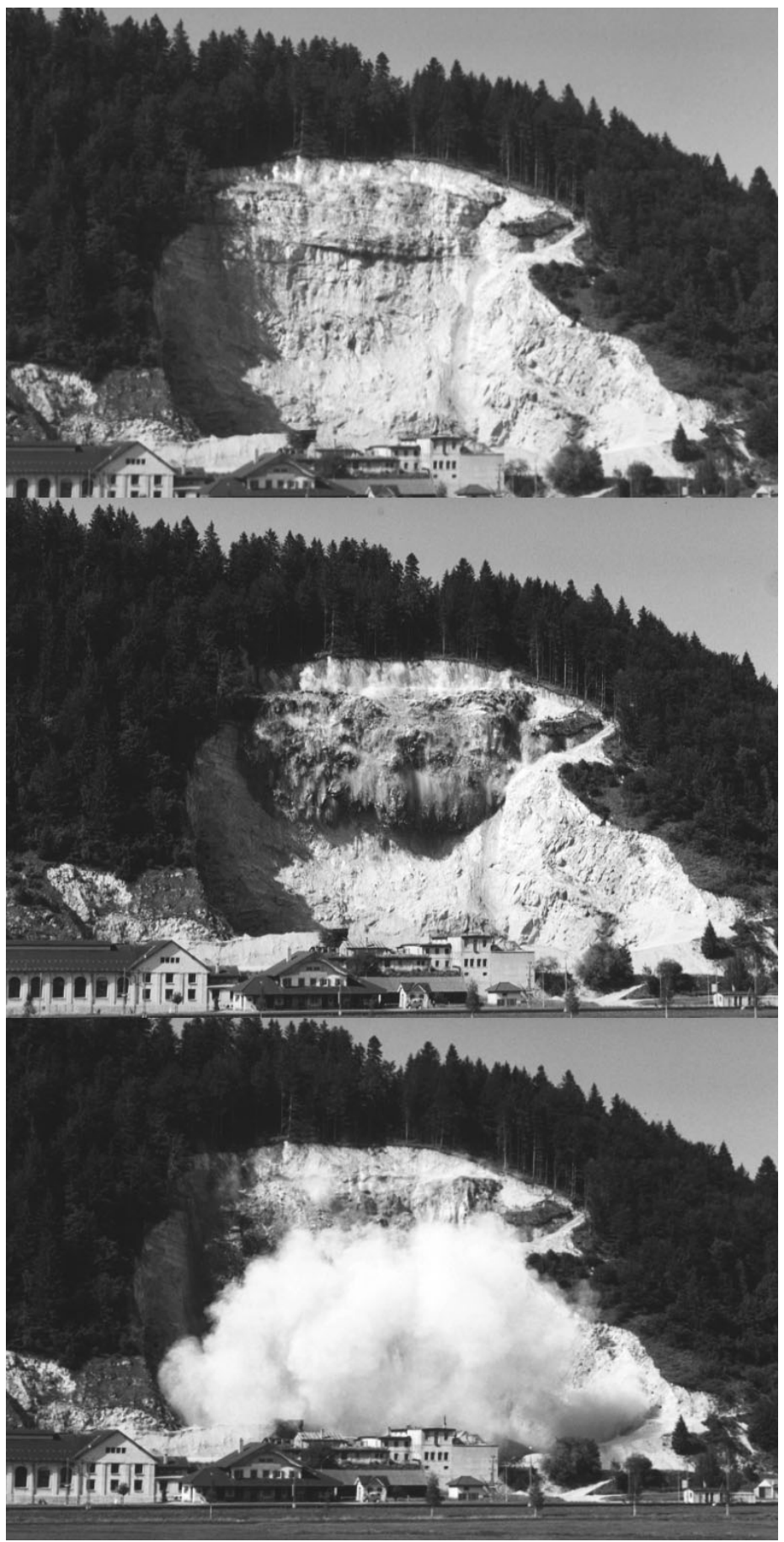

Fig. 1. Open explosive mining of $13,000 \mathrm{~m}^{3}$ Jurassic lime with $4000 \mathrm{~kg}$ ANFO and water-gel explosive. Top: immediately after ignition of the explosion. Middle: Devolution of the explosion with pushing the material without shying effect to the surrounding area. Bottom: The explosion ended with a good result. The formation of dust was normal and the infrastructure remained free of damage. 
tured either in cartridges or in pumpable bulk form [1].

\subsection{Explosives for Underground Mining}

In mining (especially coal mining), the risk of so-called firedamp explosions is high. The use of conventional explosives is therefore impossible. These atmospheric explosions are explosions of mixtures of methane ('firedamp') and air, or of coal dust and air. The shock wave created in such events extends throughout the whole gallery system. However, atmospheric explosions are not set off by the first spark which occurs. Depending on the flame temperature, ignition takes place only after a delay of up to several seconds. At $650{ }^{\circ} \mathrm{C}$ this time is about $10 \mathrm{sec}$, falling to $1 \mathrm{sec}$ at $1100{ }^{\circ} \mathrm{C}$. In order to prevent atmospheric explosions being set off, so-called permissible explosives had to be developed. These are characterised by a particularly low flame temperature in the reaction gases.

With conventional gelatinous explosives this effect is achieved by the addition of up to $40 \%$ of sodium chloride. The latter's relatively high thermal conductivity and specific heat extracts energy from the hot gas clouds, and as a result the flame temperature of the reaction gases is reduced.

High-safety explosives are materials which contain inverse salt pairs. Instead of the potentially explosive ammonium nitrate, harmless ammonium chloride and sodium nitrate are added to the formulation. If the glycerol trinitrate, which is present in low concentration is detonated, its energy remains concentrated in the drill-hole. This energy is sufficient to briefly create ammonium nitrate and sodium chloride again, which then react in the well-known way. If, however, a neighbouring charge has already carried away rock, so that the safety explosive is freely in contact with the methaneair mixture, detonation of the glycerol trinitrate only hurls off the unrestrained mixture of the inverse salt pairs, and a firedamp explosion can thereby be avoided.

\section{Tagging [2]}

\subsection{Tagging for the Identification of Commercial Explosives}

All non-military explosives used in Switzerland must include a tagging component by means of which the origin and period of manufacture can be established reliably, even after the explosion. This is stated in the ordinance issued under the Federal Law on Dangerous Explosive Materials (Explosives Ordinance), Article 18. These tagging substances are required to provide good detectability, simple storage, chemical resistance in the explosive, and suffi- cient resistance in an explosion. Currently three products are approved in Switzerland. Of these, two provide visual coding in the form of several layers of paint. These particles can be evaluated visually under the microscope. In the third product the information is present in chemical form, which makes chemical analyses necessary for decoding it. Explosive manufacturers are required to change the code after a specified quantity of explosive has been produced, or after a maximum production period.

\subsection{Tagging of Explosives for the Purpose of Detection}

As a result of the explosive attack on a Pan Am aircraft over the town of Lockerbie, the international agreement on the tagging of plastic explosives for the purpose of detection was drawn up. This has meanwhile been ratified by 91 states, including Switzerland. This form of tagging is intended as a preventive measure. With explosive-detection systems in operational use, hidden explosives are expected to be detected easier. The agreement applies to both non-military and military explosives.

\section{Detonators}

In mining and tunnel construction, and also in the demolition of buildings and other structures using explosives, the success of the operation depends on the various series of explosions being set off at specified time intervals. On one hand, the sequence of the explosion is determined by the initiation delays; on the other hand, the shock effect on the surrounding area can be greatly reduced. The need for explosive charges to be set off not simultaneously, but in a specified sequence which is defined as precisely as possible, has been a requirement placed on explosive technology from the very beginning. In earlier times, different delays were achieved by time fuses of different lengths, or by an appropriate sequence in lighting them. Today - as a result of intensive research and development highly precise electric, non-electric and electronic delayed-action ignition devices are available [3]

With electric detonators the time delay is achieved by appropriate pyrotechnic delay elements. Until the early 1950 s, only detonators with half-second intervals were available. Today detonators with short time intervals of 20 to $500 \mathrm{~ms}$ can be used, which facilitate a precise time graduation up to a maximum of $6 \mathrm{sec}$.

In non-electric detonation systems, the ignition impulse is transmitted by the detonation of very small amounts of an explosive in a plastic tube. To achieve this, the inner surface of the tube is dusted with 16 to $20 \mathrm{mg}$ of explosive per metre tube length.
After ignition, this explosive coating detonates in the tube with a velocity of 2000 $\mathrm{m} / \mathrm{s}$, so as then to ignite the delay stages of the incorporated time detonators.

With the introduction of the first electronic detonators to the market 15 years ago, detonator technology reached a new peak. Instead of the traditional pyrotechnic delay elements, electronic detonators contain an integrated switching circuit in the form of a microchip. Each detonator is provided with its own power supply, a capacitor. In respect of the structure of the explosive part, the electronic detonator is identical to a modern instantaneous igniter.

Irrespective of the delay time, with this type of detonator the scatter of the delay time is less than half a millisecond. The time interval can be programmed freely for each detonator within a range of 0 to 15,000 ms. A total of up to 1600 detonators can be used in any one blasting operation [4].

\section{Performance}

In order that debris can be cleared away efficiently and further use of the material produced by the blast is not restricted, the rock must not be broken down into excessively small pieces by blasting. In mining and tunnel construction, explosives are used which are highly effective in moving material (work capacity) but have a limited shattering effect (brisance). The high propulsive blast effect of non-military explosives is based on their high explosion heat and the large quantity of reaction gases which are released in the detonation. In comparison to military formulations, nonmilitary explosives exhibit a lower detonation velocity, as well as lower pressure and temperature in the detonation front. This results in a lesser shattering effect on the immediate surrounding area. This behaviour is mainly attributable to the fact that non-military explosives exhibit a markedly lower density, as well as a high proportion of nonideal conversion in the detonation. Table 2 presents the performance data of a choice of commercial high explosives.

\section{Explosive Plating}

In addition to mining and tunnel construction, non-military explosives are also used for a large number of special applications, such as building demolition, setting off avalanches, seismic investigations, blasting of drainage channels in the oil industry and also in metal-forming technology.

A further special application is explosive plating. This process enables various metals to be joined which cannot be welded conventionally. The resulting thin layers 
Table 2. Performance data of non-military explosives. In the lead-block test, the expansion of a defined cavity caused by detonation of the substance is measured.

\begin{tabular}{|c|c|c|c|c|c|}
\hline Name & $\begin{array}{l}\text { Type } \\
\text { (used as) }\end{array}$ & Density & $\begin{array}{l}\text { Detonation } \\
\text { velocity } \\
{[\mathrm{m} / \mathrm{s}]}\end{array}$ & $\begin{array}{l}\text { Lead-block } \\
\text { expansion test } \\
{\left[\mathrm{cm}^{3} / 10 \mathrm{~g}\right]}\end{array}$ & $\begin{array}{l}\text { Gas volume } \\
{[1 / \mathrm{kg}]}\end{array}$ \\
\hline Gamsit A & $\begin{array}{l}\text { gelatinous } \\
\text { (cartridge) }\end{array}$ & 1.40 & 6200 & 420 & 850 \\
\hline $\begin{array}{l}\text { Gotthardit } \\
100\end{array}$ & $\begin{array}{l}\text { slurry } \\
\text { (cartridge) }\end{array}$ & 1.20 & 4700 & - & 715 \\
\hline Tovex S & $\begin{array}{l}\text { water-gel } \\
\text { (cartridge) }\end{array}$ & 1.30 & 4000 & 380 & 650 \\
\hline Emulga & $\begin{array}{l}\text { emulsion } \\
\text { (pumped) }\end{array}$ & $0.95-1.15^{a}$ & $3900-4500$ & $\begin{array}{l}\text { cannot be } \\
\text { measured: not } \\
\text { sensitive to cap }\end{array}$ & $\max .960$ \\
\hline
\end{tabular}

of the joint metals have high mechanical strength. For example, in the shipbuilding industry, aluminium can be plated onto steel. With the aid of stripes of such connecting elements, light aluminium superstructures can then be mounted on the massive steel hull by means of conventionally welded joints, without the use of rivets. In the chemical industry this technology is used for the manufacture of reactor vessels which are resistant to chemicals. To achieve this, thin layers of titanium are plated onto steel, which serves as the base metal.

The process of explosive plating is shown in Fig. 2. In preparation, the cladding and base metal mating surfaces are ground and then fixtured parallel at a precise spacing. A measured quantity of a specifically formulated explosive is placed on the cladding metal surface. The detonation front travels uniformly across the surface from initiation. The cladding metal beneath the detonating explosive is propelled to collide with the base metal at a specific impact velocity and angle. The resulting momentum exchange causes a thin layer of material to be spalled from the mating surfaces preceding the collision point. An en- ergetic 'jet' comprised of the spalled materials ejects metal oxides and surface debris as the detonation front progresses. The mating surfaces collide under pressure of several million pounds per square inch. The combination of surface cleaning and extreme pressure produces a very thin continuous metallurgical weld [5].

Received: March 30, 2004

[1] W. Thum, 'Sprengtechnik im Steinbruch und Baubetrieb', Bauverlag, 1978, ISBN 3-7625-0505-5.

[2] Statement of K. Schlatter and J. Schärer, Wissenschaftlicher Forschungsdienst Stadt Zürich, 2004.

[3] O. Ringgenberg, A. Egger, 'Felstechnik', sprengtechnisches Handbuch für den Praktiker, Gasser Felstechnik AG, 2003.

[4] J. Petzold, F. Hammelmann, Orica Germany $\mathrm{GmbH}$, Troisdorf. Nobel Heft $1 / 2000$.

[5] www.dynamicmaterials.com/clad/ detaclad.htm

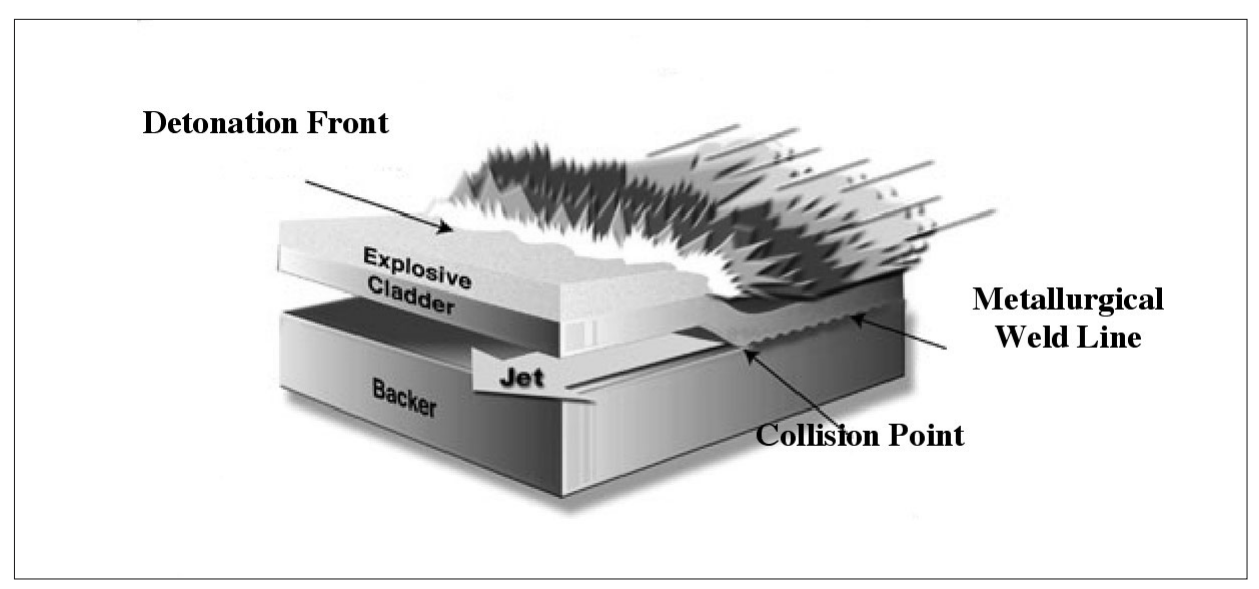

Fig. 2. The DETACLAD ${ }^{\circledR}$ process creates a high-strength, ductile, metallurgical weld 